\title{
BMJ Open Understanding pathways to inequalities in child mental health: a counterfactual mediation analysis in two national birth cohorts in the UK and Denmark
}

To cite: Lai ETC, Schlüter DK, Lange T, et al. Understanding pathways to inequalities in child mental health: a counterfactual mediation analysis in two national birth cohorts in the UK and Denmark. BMJ Open 2020;10:e040056. doi:10.1136/ bmjopen-2020-040056

- Prepublication history and additional material for this paper is available online. To view these files, please visit the journal online (http://dx.doi.org/10. 1136/bmjopen-2020-040056).

Received 04 May 2020 Revised 13 August 2020 Accepted 07 September 2020

\section{Check for updates}

(C) Author(s) (or their employer(s)) 2020. Re-use permitted under CC BY. Published by BMJ.

${ }^{1}$ Institute of Population Health Sciences, University of Liverpool, Liverpool, UK

${ }^{2}$ Section of Epidemiology, Department of Public Health, University of Copenhagen, Copenhagen, Denmark ${ }^{3}$ Section of Biostatistics, Department of Public Health, University of Copenhagen, Copenhagen, Denmark ${ }^{4}$ Centre for Statistical Science, Peking University, Beijing, China ${ }^{5}$ Aging Research Center, Karolinska Institute \& Stockholm University, Stockholm, Sweden

Correspondence to

Dr Eric TC Lai;

etcl@liverpool.ac.uk

\section{ABSTRACT}

Objectives We assessed social inequalities in child mental health problems (MHPs) and how they are mediated by perinatal factors, childhood illness and maternal mental health in two national birth cohorts. Design Longitudinal cohort study

Setting We used data from the UK Millennium Cohort Study and the Danish National Birth Cohort.

Primary and secondary outcome measures We applied causal mediation analysis to longitudinal cohort data. Socioeconomic conditions (SECS) at birth were measured by maternal education. Our outcome was child MHPs measured by the Strength and Difficulty Questionnaire at age 11. We estimated natural direct, indirect and total effects (TEs) of SECs on MHPs. We calculated the proportion mediated (PM) via three blocks of mediatorsperinatal factors (smoking/alcohol use during pregnancy, birth weight and gestational age), childhood illness and maternal mental health.

Results At age 11 years, $9 \%$ of children in the UK and $3.8 \%$ in Denmark had MHPs. Compared with high SECs, children in low SECs had a higher risk of MHPs (relative risk $(R R)=4.3,95 \%$ Cl 3.3 to 5.5 in the UK, $n=13112$; and $\mathrm{RR}=6.2,95 \% \mathrm{Cl} 4.9$ to 7.8 in Denmark, $\mathrm{n}=35 \mathrm{764})$. In the UK, perinatal factors mediated $10.2 \%(95 \% \mathrm{Cl} 4.5$ to 15.9$)$ of the TE, and adding maternal mental health tripled the PM to $32.2 \%$ (95\% Cl 25.4 to 39.1). In Denmark, perinatal factors mediated $16.5 \%(95 \% \mathrm{Cl} 11.9$ to 21.1$)$ of the $\mathrm{TE}$, and including maternal mental health increased the PM to $16.9 \%$ (95\% Cl 11.2 to 22.6$)$. Adding childhood illness made little difference in either country.

Conclusion Social inequalities in child mental health are partially explained by perinatal factors in the UK and Denmark. Maternal mental health partially explained inequalities in the UK but not in Denmark.

\section{INTRODUCTION}

Child and adolescent mental health problems (MHPs) constitute a substantial disease burden $^{1}$ affecting $10 \%$ to $20 \%$ of adolescents globally, ${ }^{2}$ with around half of all lifetime cases of mental health disorders emerging by age $14 .^{3}$ Few studies have compared the social

\section{Strengths and limitations of this study}

- We used two large contemporary cohorts in Europe with a wide range of information collected.

- Modern methods of causal mediation analysis were used to assess mediation by the putative mediators.

- One of the major limitations was that analysis could only be carried out in a harmonised manner across the two birth cohorts.

- As with most of the longitudinal cohort studies, missing data is inevitable and hence a challenge for analysis.

distribution and prevalence of MHPs across countries. One study from 2008 showed significant variation in MHPs across European countries, and on the basis of socioeconomic status, with the highest prevalence reported in the $\mathrm{UK}{ }^{4}$ In the UK, according to the most recent longitudinal population-level data, child MHPs are increasingly common. One in eight children aged 10 to 15 years reported socioemotional behavioural problems from 2011 to 2012, compared with one in 10 in 2004. ${ }^{5}$ According to some studies, Scandinavian countries like Denmark have also experienced an increase in incidence of child MHPs. $^{6}$

There are clear social inequalities in child and adolescent MHPs on the basis of childhood socioeconomic conditions (SECs), as commonly measured by parental education, income or occupation. A systematic review of studies of the association between childhood SECs and child MHPs found that children growing up in disadvantaged childhood SECs were two to three times more likely to develop MHPs than their more advantaged peers, across studies in 23 countries. ${ }^{7}$ Social inequalities in MHPs are evident early in life ${ }^{8}$ and track strongly to adulthood. ${ }^{9}$ 
Few studies have assessed mediating pathways by which childhood SECs influence the risk of MHPs during late childhood/early adolescence. ${ }^{710}$ There are many potential pathways, whereby children growing up in more disadvantaged SECs are more exposed or vulnerable to risk factors for subsequent MHPs. Studies have shown that infants born with low birth weight have a higher risk of MHPs in young adulthood, ${ }^{11}$ and birth weight is highly socially patterned. ${ }^{12}$ Moreover, maternal smoking during pregnancy, also a socially patterned risk factor, may be associated with higher risk of conduct problems in children. ${ }^{14}$ Social disadvantage is associated with greater stress in parents and subsequent parental MHPs, impacting caregiving behaviours and quality. ${ }^{15}$ In addition, risk factors intrinsic to the child such as chronic childhood illness are more common in children growing up in disadvantaged SECs, and may impact on subsequent risk of MHPs. ${ }^{16}$

Mäntymaa and colleagues categorise risk factors for child psychopathology as risks in the child, the parents and the social context. ${ }^{17}$ Using this framework, we previously showed the importance of early years mediators in the UK, particularly perinatal factors, such as birth weight and gestational age, and family factors such as maternal MHPs. ${ }^{10}$ Building on these findings, we aimed to compare causal pathways to inequalities in child MHPs in the UK and Denmark. We hypothesised that children growing up in more disadvantaged SECs are at increased risk of MHPs due to increased exposure to perinatal, maternal and child level risk factors. We further hypothesised that these pathways may differ across country contexts. In order to identify modifiable policy entry points to reduce inequalities in MHPs, we therefore compare pathways to MHPs in late childhood/early adolescence in two rich birth cohorts in the UK and Denmark.

\section{METHODS}

\section{Study population}

The Millennium Cohort Study (MCS) is a large nationally representative cohort of children born in the UK between September 2000 and January 2002 who have been followed up through six survey waves, when aged 9 months, and 3, 5, 7, 11 and 14 years. ${ }^{18}$ The MCS initially recruited 19244 families, of which 13112 participated in follow-up at age 11. The Danish National Birth Cohort (DNBC) is a population-based cohort study. Between 1996 and 2002, 100415 pregnant women, representing 30\% of all pregnancies in Denmark during that period, were recruited at the first antenatal care visit with their general practitioner. ${ }^{19}$ These pregnancies resulted in 96853 live births out of which 35764 participated in follow-up at age 11 (online supplemental figure 1).

\section{Exposure}

Our primary exposure of interest was highest qualification attained by the mother at the time of their child's birth. This is a common measure of childhood SECs used in social epidemiological studies ${ }^{20}$ and previous cross cohort comparisons of UK and Danish populations. ${ }^{21}$ Details on how this measure was recorded are in the online supplemental appendix. We scaled the education measure in each country in order to derive the relative index of inequality in our models (RII) ${ }^{22}$ The RII compares the risk of MHPs between children of highest and lowest SECs, taking into account the distribution of education level in the study population by ranking the maternal education groups from high to low and allocating a score (ranging from 0 to 1 ) that represents the midpoint of the category's range in the cumulative distribution (online supplemental appendix). We used this score as a continuous exposure variable in our regression model. The exponentiated coefficient gives a relative risk (RR), comparing children with highest and lowest SECs at birth. ${ }^{22}$

\section{Outcome}

The main outcome of interest was MHPs measured at age 11, the longest follow-up that is currently captured in both cohorts, using the Strengths and Difficulties Questionnaire $(\mathrm{SDQ})$ based on maternal report (online supplemental appendix). The SDQ has been shown to be a reliable screening instrument for emotional and behavioural problems in school-age children, ${ }^{23}$ and has good internal consistency. ${ }^{15}$ We used the well-established UK cut-offs for MCS, that is, 0 to 16 indicates normal to borderline behaviour and 17 to 40 indicates MHPs. ${ }^{24}$ For DNBC, the cut-offs were: $\geq 17$ for boys and $\geq 15$ for girls indicating MHPs. ${ }^{25}$

\section{Potential mediators}

In our previous study, we identified a range of childhood risk factors that potentially explain the social inequalities in adolescent mental health. ${ }^{10}$ We mapped these potential mediators to those available at similar time points across both cohorts. These are shown in table 1, grouped into three categories: perinatal factors, childhood illness and maternal mental health.

\section{Covariates}

Confounders were chosen on the basis of common causes of exposure (maternal education), mediators and outcome (MHPs at age 11 years). ${ }^{26}$ Previous history of maternal MHPs and maternal age were considered to be confounders (online supplemental figure 2) (online supplemental appendix). We also adjusted for sex in our models.

\section{Statistical analysis}

We undertook causal mediation analysis under the counterfactual framework to partition the total effect (TE) of maternal education on MHPs at age 11 years acting through the proposed mediators (natural indirect effect (NIE)) and through mechanisms that bypass the putative mediators (natural direct effect (NDE)) (online supplemental appendix). 
Table 1 Description of mediator variables

\begin{tabular}{lll}
\hline & Description & \\
\cline { 2 - 3 } Variables & DNBC & MCS \\
\hline
\end{tabular}

Perinatal factors

Mothers were asked at, on average, 16 to 17 weeks of gestational age whether they smoked during pregnancy (yes/no)

Mothers were asked when the child was 9 months old whether they smoked before pregnancy (yes/no), and whether they changed after becoming pregnant (yes/no). Those who did not give up smoking during pregnancy were considered having smoked during pregnancy

\begin{tabular}{|c|c|c|}
\hline $\begin{array}{l}\text { Alcohol use in } \\
\text { pregnancy }\end{array}$ & $\begin{array}{l}\text { Mothers were asked at, on average, } 16 \text { to } 17 \text { weeks } \\
\text { of gestational age about the number of units of } \\
\text { alcoholic beverage namely beer, wine and spirit, } \\
\text { that the mothers drank per week. Amount of alcohol } \\
\text { consumption was categorised as: (1) did not drink } \\
\text { alcohol during pregnancy; (2) light drinker: one to } \\
\text { two units per week; (3) moderate drinker: three to six } \\
\text { units per week; and (4) heavy drinker: seven units or } \\
\text { more. }{ }^{41} \text { However, only a few observations falls into } \\
\text { the category of heavy drinker ( } \mathrm{n}<10 \text { ); we collapsed } \\
\text { the heavy drinker category into moderate drinker. A } \\
\text { unit of alcohol was defined as one bottle of beer, one } \\
\text { glass of wine, or one glass of spirits (about } 4 \mathrm{cL} \text { ), } \\
\text { each of which corresponds to about } 12 \mathrm{~g} \text { of alcohol }{ }^{42}\end{array}$ & $\begin{array}{l}\text { Mothers were asked when the child was } 9 \text { months } \\
\text { old if they drank alcohol during pregnancy, the } \\
\text { number of units they consumed per week. Amount of } \\
\text { alcohol consumption was categorised as: (1) did not } \\
\text { drink alcohol during pregnancy; ( } 2 \text { ) light drinker: one } \\
\text { to two units per week; (3) moderate drinker: three } \\
\text { to six units per week; and (4) heavy drinker: seven } \\
\text { units or more. }{ }^{41} \text { The heavy drinker category was } \\
\text { collapsed into moderate drinker category as some } \\
\text { cells only had small number of observations ( } \mathrm{n} \sim 10 \text { ) } \\
\text { when cross-tabulated with maternal education. A unit } \\
\text { of alcohol was defined as approximately half a pint } \\
\text { of beer or one glass of wine, which is around } 10 \mathrm{~g} \text { of } \\
\text { alcohol }\end{array}$ \\
\hline Birth weight & $\begin{array}{l}\text { Data on birth weight in grams were obtained by } \\
\text { data linkage to the Danish medical birth registry of } \\
\text { Denmark }\end{array}$ & $\begin{array}{l}\text { Mothers were asked when the child was } 9 \text { months } \\
\text { old about the birth weight of their child, in kilograms } \\
\text { or pounds. Birth weights were then converted to } \\
\text { grams for analysis }\end{array}$ \\
\hline Gestational age & $\begin{array}{l}\text { Data on gestational age in days were obtained by } \\
\text { data linkage to the Danish medical birth registry of } \\
\text { Denmark }\end{array}$ & $\begin{array}{l}\text { Gestational age in days was calculated on the basis } \\
\text { of the mother's report of her expected due date }\end{array}$ \\
\hline $\begin{array}{l}\text { Childhood illness at } \\
\text { age } 7 \text { years }\end{array}$ & $\begin{array}{l}\text { Mothers were asked whether the child had any } \\
\text { handicap or chronic illness (yes/no) }\end{array}$ & $\begin{array}{l}\text { Mothers were asked whether the child had any } \\
\text { longstanding illness/disability/infirmity (yes/no) }\end{array}$ \\
\hline $\begin{array}{l}\text { Maternal mental } \\
\text { health at age } 7 \text { years }\end{array}$ & $\begin{array}{l}\text { Mothers were asked whether she had a psychiatric } \\
\text { illness/bad nerve since birth (yes/no) }\end{array}$ & $\begin{array}{l}\text { Maternal psychological distress was assessed using } \\
\text { Kessler- } 6 \text { scale, }{ }^{45} \text { asking whether in the last month } \\
\text { how often respondents felt depressed, hopeless, } \\
\text { restless or fidgety, worthless or that everything was } \\
\text { an effort. Validated cut-off scores were used: normal } \\
(0 \text { to 5); distress ( } 6 \text { to } 24)\end{array}$ \\
\hline
\end{tabular}

DNBC, Danish National Birth Cohort; MCS, Millennium Cohort Study.

Our understanding of the temporal sequence of mediators ${ }^{9}$ and the timing of measurement led us to choose a sequential approach to causal mediation analysis. We used logistic regression adjusted for maternal mental health before and during pregnancy and maternal age. We built three models (online supplemental appendix figure 1). Model 1 estimated the NIE through perinatal factors, including paths that operate through the downstream causal descendants of perinatal factors, but excluding the paths operating directly through childhood illness and/or maternal mental health at age 7 years. Model 2 estimated the NIE through both perinatal factors and childhood illness at age 7 years and their causal descendants but excluded the paths operating through maternal mental health at age 7 years. Model 3 estimated the NIE through perinatal factors, childhood illness and maternal mental health at age 7 years, encompassing all possible pathways but excluding the NDE from maternal education to mental health at age 11 years. We estimated the RR and $95 \%$ CI for the NDE, NIE and TE sequentially, using the medflex package in R (V.3.5.1), ${ }^{27}$ which parameterises the path-specific effects of interest in the presence of multiple mediators, taking into account potential interactions between the variables included in the mediating blocks. ${ }^{27}$ We also estimated the proportion mediated (PM) in each model using the formula ${ }^{28}$ :

$$
\frac{\mathrm{RR}_{\mathrm{NDE}}\left(\mathrm{RR}_{\mathrm{NIE}}-1\right)}{\left(\mathrm{RR}_{\mathrm{NDE}} \times \mathrm{RR}_{\mathrm{NIE}}-1\right)}
$$

The $95 \%$ CI for the PM were calculated using nonparametric bootstrapping for 1000 iterations. For the mediation analysis to have a causal interpretation, we assume no exposure-mediator interaction, that adjustment for confounding between exposure-mediator, mediator outcome and exposure outcome has been addressed, and that there is no post-treatment confounding. ${ }^{28}$ In 
both cohorts, we used multiple imputation to handle missing data (online supplemental appendix).

\section{Robustness tests}

To test the robustness of our findings, we conducted sensitivity analyses. First, we repeated the analysis on the absolute risk scale using a linear probability model. The estimates derived from this model give the risk difference across extremes of the maternal education gradient (also interpretable as the slope index of inequality). Second, we checked for the presence exposure-mediator interaction by repeating Model 3, this time allowing for all twoway interactions between maternal education and the mediators in the model. We used a likelihood ratio test to examine if the model with interactions between maternal education and all mediators provided the better fit. Third, we undertook complete case analysis for those with complete observations for exposure, outcome, mediators and covariates. Fourth, we repeated the MCS analysis applying survey weights to account for sampling design and attrition (online supplemental appendix). Fifth, we repeated analyses using alternative measures of maternal mental health conditions at child age 7 years. The MCS questionnaire asked mothers whether they were ever diagnosed with depression or anxiety. We only considered the reported diagnoses after childbirth. In DNBC, we linked mothers' Det Centrale Personregister (CPR) number to hospital records via Statistics Denmark for any hospital contact for psychiatric illness since the child's birth. Finally, we conducted a bias analysis for unmeasured confounding, which assessed the sensitivity of the results to unmeasured confounding of the mediatoroutcome association using Vanderweele's bias formula (online supplemental appendix). ${ }^{29}$

\section{Patient and public involvement}

Patients and the public were not involved in this research.

\section{RESULTS}

\section{Baseline characteristics}

At age 11 years, $9 \%$ of children had MHPs in the UK, compared with 3.7\% in Denmark (table 2). In both cohorts, mothers with lower education were more likely to be younger, have worse mental health, have smoked or consumed alcohol during pregnancy and have worse mental health when the child was 7 years old. Also, in both cohorts, children of mothers with lower education were more likely to have lower birth weight, shorter gestational age and longstanding illness at age 7 years (figure 1).

\section{Causal mediation analysis}

In both cohorts, lower maternal education was associated with worse mental health at age 11. The TE of maternal education on MHPs (a RR comparing children with the highest and lowest SECs interpretable as the RII) for MCS children was 4.28 (95\% CI 3.30 to 5.54) and for DNBC the TE was 6.21 (95\%CI 4.94 to 7.80$)$. In MCS, perinatal
Table 2 Baseline characteristics of cohort participants in the UK MCS in wave 5 (age 11 years) and the DNBC at age 11 years

\section{MCS}

$\mathrm{n}(\%)$ for categorical variables or mean (SD) for continuous variables

\section{Characteristics}

\begin{tabular}{|c|c|}
\hline$n$ & 13112 \\
\hline \multicolumn{2}{|l|}{ Maternal education } \\
\hline Higher degree & $467(3.8)$ \\
\hline First degree & $1834(14.9)$ \\
\hline Diplomas in higher education & $1123(9.1)$ \\
\hline A/AS/S levels & $1266(10.3)$ \\
\hline GCSE grades $A$ to $C$ & $4197(34.2)$ \\
\hline GCSE grades $D$ to $G$ & $1285(10.5)$ \\
\hline None & $2103(17.1)$ \\
\hline Maternal mental health problem history & $3116(24.7)$ \\
\hline Boys & $6390(50.5)$ \\
\hline Maternal age (years) (SD) & $29.53(5.9)$ \\
\hline $\begin{array}{l}\text { Socioemotional behavioural problem } \\
(\mathrm{SDQ} \text { score } \geq 17 \text { ) }\end{array}$ & $1130(9.0)$ \\
\hline Birth weight (kg) (SD) & $3.37(0.58)$ \\
\hline Maternal smoking during pregnancy & $1867(14.8)$ \\
\hline \multicolumn{2}{|l|}{ Alcohol drinking during pregnancy } \\
\hline Never & $11505(91.0)$ \\
\hline 1 to 2 units per week & $557(4.4)$ \\
\hline$\geq 3$ units per week & $580(4.6)$ \\
\hline Gestational age (days) (SD) & $276.20(13.5)$ \\
\hline Child's longstanding illness at age 7 years & $2195(18.5)$ \\
\hline $\begin{array}{l}\text { Maternal mental health problem at child } \\
\text { age } 7 \text { years }\end{array}$ & $2083(18.9)$ \\
\hline (Kessler-6 score $\geq 6$ ) & \\
\hline
\end{tabular}

\section{DNBC}

$\mathrm{n}(\%)$ for categorical variables or mean (SD) for continuous variables

\section{Characteristics}

$\mathrm{n}$ 35764

Maternal education

Masters or above 3851 (10.8)

Bachelor or equivalent 10789 (30.3)

Short cycle tertiary $2074(5.8)$

Upper secondary 15948 (44.7)

Lower secondary or lower 2992 (8.4)

Maternal mental health problem history

$2290(6.7)$

Boys $17920(50.1)$

Maternal age (years) (SD) 30.36 (4.2)

Continued 


\begin{tabular}{|c|c|}
\hline \multicolumn{2}{|l|}{ DNBC } \\
\hline $\begin{array}{l}\text { Socioemotional behavioural problem } \\
\text { (SDQ score } \geq 17 \text { ) }\end{array}$ & $1375(3.8)$ \\
\hline Birth weight (kg) (SD) & $3.57(0.6)$ \\
\hline Maternal smoking during pregnancy & $7193(20.9)$ \\
\hline \multicolumn{2}{|l|}{ Alcohol drinking during pregnancy } \\
\hline Never & $25525(74.2)$ \\
\hline 1 to 2 units per week & 7875 (22.9) \\
\hline$\geq 3$ units per week & $980(2.9)$ \\
\hline Gestational age (days) (SD) & $279.15(12.8)$ \\
\hline Child's longstanding illness at age 7 years & $2114(6.0)$ \\
\hline $\begin{array}{l}\text { Maternal mental health problem at child } \\
\text { age } 7 \text { years } \\
\text { (Kessler- } 6 \text { score } \geq 6 \text { ) }\end{array}$ & $4736(13.6)$ \\
\hline
\end{tabular}

DNBC, Danish National Birth Cohort ; GCSE, General Certificate of Secondary Education; MCS, Millennium Cohort Study; SDQ, Strengths and Difficulties Questionnaire.

factors mediated $10.17 \%$ of the TE (95\% CI 4.47 to 15.87 ) (table 3). Adding childhood illness at 7 years in the model yielded little change to the PM $(11.53 \%, 95 \%$ CI 5.20 to 17.86). However, adding maternal mental health at age 7 years almost tripled the PM $(32.31 \%, 95 \%$ CI 25.37 to 39.06). In DNBC, perinatal factors mediated $16.47 \%$ of the TE (95\% CI 11.88 to 21.06). As in the MCS, adding childhood illness at age 7 years did not substantially affect the PM $(15.59 \%, 95 \%$ CI 9.86 to 21.31). Unlike in the
MCS, adding maternal mental health at age 7 years made little difference to the PM $(16.91 \%, 95 \%$ CI $11.17 \%$ to $22.64 \% ; \mathrm{RR}_{\mathrm{NIE}} 1.16 ; 95 \%$ CI 1.10 to 1.23$)$.

\section{Robustness tests}

First, the analysis using the absolute risk scale showed a larger TE of maternal education on MHPs in the UK (10 percentage points, 95\% CI 7 to 13) compared with Denmark (6 percentage points, $95 \%$ CI 5 to 7 ) (online supplemental table 1). The pattern of mediation on the absolute scale was similar to that on the relative scale. Second, models with all two-way interaction terms did not have a better fit in either cohort (likelihood ratio test $p$ value $>0.05$ ). Third, repeating the analysis using complete cases showed similar patterns of mediation as in the main analysis (online supplemental table 2). Fourth, applying survey weights in the MCS data also yielded similar patterns of mediation, though estimates were slightly attenuated (online supplemental table 3 ). Fifth, we used alternative measures of maternal mental health at age 7 years in both cohorts. In MCS, using maternal reported 'ever diagnosis of depression' led to a reduced PM in Model 3 (11.19\%, 95\%CI 4.82 to 17.56). In DNBC, using any psychiatric diagnosis as captured in the population registry did not alter the results (online supplemental table 4). Finally, the bias analysis showed that the estimated NIEs were robust to the presence of moderate unmeasured confounding (online supplemental table 5).
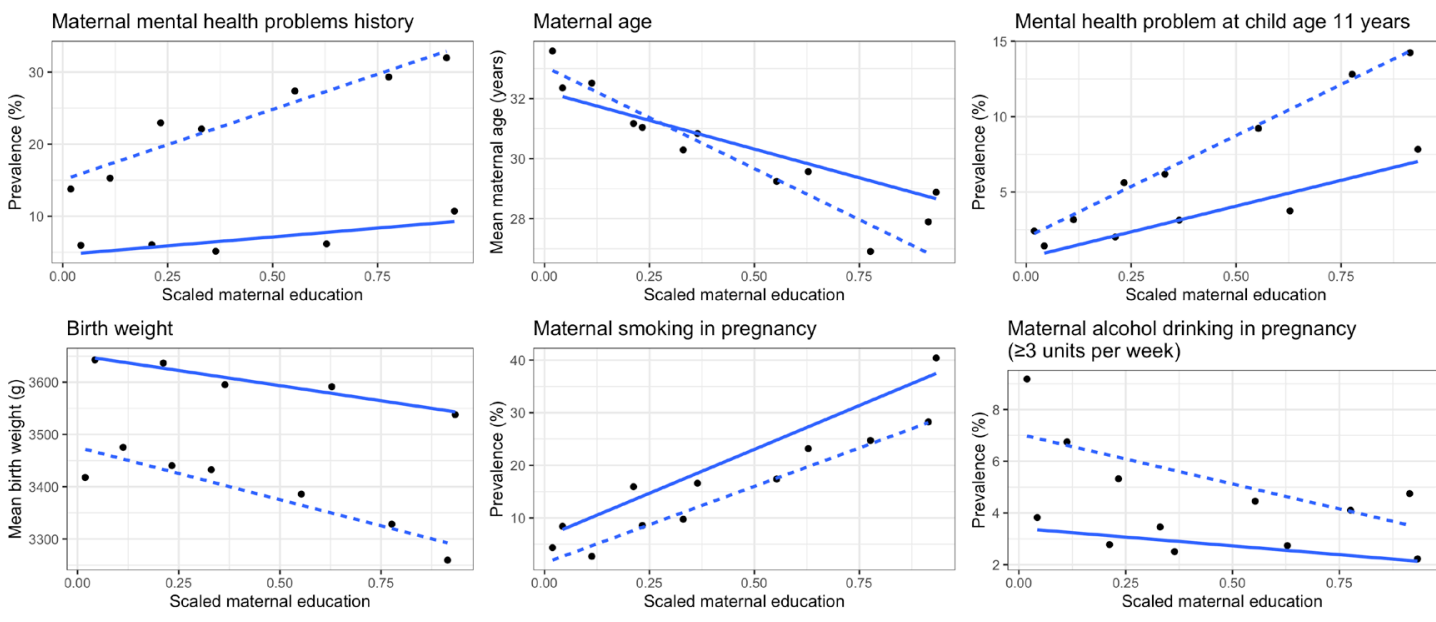

Maternal smoking in pregnancy

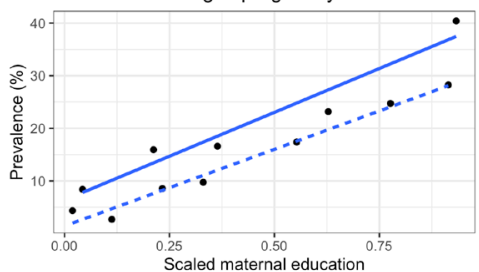

Maternal alcohol drinking in pregnancy ( $\geq 3$ units per week)

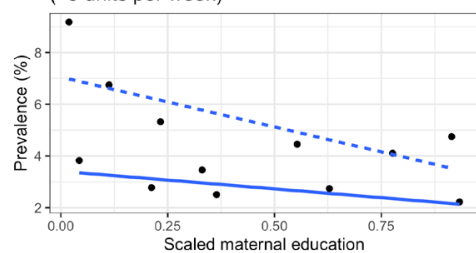

Gestational age
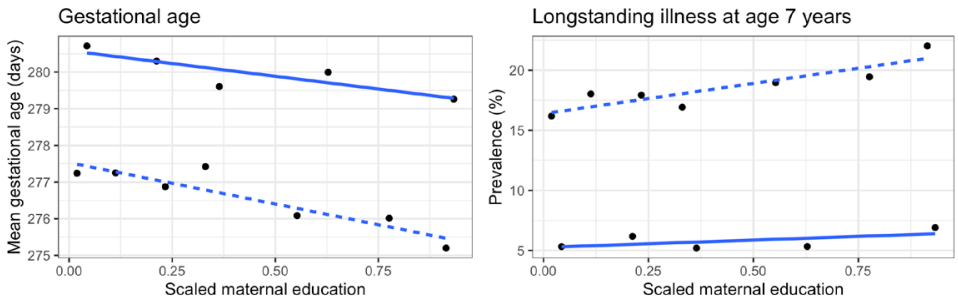

Maternal mental health problem at child age 7 years

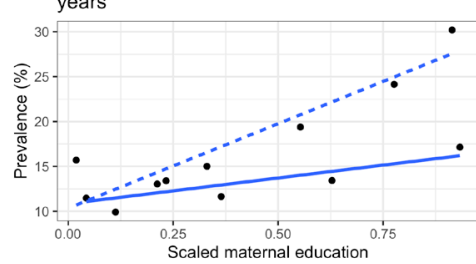

cohort - DNBC - - MCS

Figure 1 Socioeconomic gradient of baseline characteristics in the UK MCS and the DNBC. DNBC, Danish National Birth Cohort; MCS, Millennium Cohort Study. 
Table 3 Estimates from causal mediation analysis for the association of maternal education and socioemotional behavioural problems at age 11 years in the UK MCS and the DNBC

\begin{tabular}{|c|c|c|c|c|c|}
\hline Mediator & Effect & $\mathrm{RR}$ & $95 \% \mathbf{C l}$ & PM & $95 \% \mathbf{C l}$ \\
\hline \multicolumn{6}{|l|}{ MCS } \\
\hline Perinatal factors & Natural direct effect & 3.95 & 3.05 to 5.12 & 10.17 & 4.47 to 15.87 \\
\hline Perinatal factors & Natural indirect effect & 1.08 & 1.03 to 1.14 & . & . \\
\hline Perinatal factors & Total effect & 4.28 & 3.30 to 5.54 & . & . \\
\hline+ Childhood illness at age 7 years & Natural direct effect & 3.89 & 3.01 to 5.04 & 11.53 & 5.20 to 17.86 \\
\hline+ Childhood illness at age 7 years & Natural indirect effect & 1.09 & 1.04 to 1.16 & . & . \\
\hline +Childhood illness at age 7 years & Total effect & 4.28 & 3.30 to 5.54 & . & . \\
\hline +Maternal mental health at age 7 years & Natural direct effect & 3.15 & 2.44 to 4.06 & 32.21 & 25.37 to 39.06 \\
\hline +Maternal mental health at age 7 years & Natural indirect effect & 1.33 & 1.23 to 1.44 & . & . \\
\hline +Maternal mental health at age 7 years & Total effect & 4.28 & 3.30 to 5.54 & . & . \\
\hline \multicolumn{6}{|l|}{ DNBC } \\
\hline Perinatal factors & Natural direct effect & 5.26 & 4.16 to 6.64 & 16.47 & 11.88 to 21.06 \\
\hline Perinatal factors & Natural indirect effect & 1.16 & 1.11 to 1.21 & . & . \\
\hline Perinatal factors & Total effect & 6.21 & 4.94 to 7.80 & . & . \\
\hline +Childhood illness at age 7 years & Natural direct effect & 5.25 & 4.17 to 6.61 & 15.59 & 9.86 to 21.31 \\
\hline +Childhood illness at age 7 years & Natural indirect effect & 1.15 & 1.09 to 1.21 & . & . \\
\hline +Childhood illness at age 7 years & Total effect & 6.21 & 4.94 to 7.80 & . & . \\
\hline +Maternal mental health at age 7 years & Natural direct effect & 5.19 & 4.12 to 6.53 & 16.91 & 11.17 to 22.64 \\
\hline +Maternal mental health at age 7 years & Natural indirect effect & 1.16 & 1.10 to 1.23 & . & . \\
\hline +Maternal mental health at age 7 years & Total effect & 6.21 & 4.94 to 7.80 & . & . \\
\hline
\end{tabular}

.DNBC, Danish National Birth Cohort; MCS, Millennium Cohort Study; PM, proportion mediated; RR, relative risk.

\section{DISCUSSION}

Using national birth cohort data from two countries, our study shows that children in the UK have higher prevalence of MHPs at age 11 years compared with children in Denmark. Relative inequalities were stark in both countries, with roughly four times and six times higher risk for children at bottom of SECs scale compared with the top, in the UK and Denmark, respectively. Absolute inequalities were larger in the UK. Perinatal factors explained $10 \%$ of the social inequality in the UK and $16 \%$ in Denmark. By contrast, maternal mental health was an important mediator only in the UK in our primary analysis, with the final model explaining $32 \%$ of the relative inequality at age 11 years.

\section{Comparison with other studies}

In this study, we found that in the UK sample, by age 11 years, around $9 \%$ of children had MHPs, whereas in Denmark the figure was around $3.7 \%$. These findings broadly correspond with recent findings that one in 10 UK children aged 5 to 15 years of age has MHPs. ${ }^{30}$ While we lack contemporary comparative data on child mental health, our findings corroborate the Kidscreen study from 2008, which examined 15945 adolescents across 13 European countries using adolescent self-reported SDQ. The authors found that the UK had the worst adolescent mental health, with the largest effect size for the association of low SECs on SDQ score. The study did not include Denmark, but the low prevalence of MHPs in DNBC are comparable to findings for Germany $(2.9 \%)$ and Switzerland $(3.6 \%){ }^{4}$

Our results show clear social inequalities in MHPs in adolescents in both the UK and Denmark. This finding is corroborated by numerous previous studies, which showed a socioeconomic gradient of MHPs in children/ adolescents in various settings. ${ }^{7}$ Relative inequalities were similar in both countries, with a greater point estimate in Denmark. However, relative inequalities can increase when the overall prevalence in the population is low, ${ }^{31}$ as is the case for MHPs in Denmark. On the absolute scale, inequalities were larger in the $\mathrm{UK}$, with a 10 percentage point difference across the maternal education hierarchy, compared with 6 percentage points in Denmark.

Our study showed that perinatal factors (smoking and alcohol use in pregnancy, gestational age and birth weight) explained around $10 \%$ of the socioeconomic gradient of MHPs in late childhood/early adolescence. Both maternal smoking and alcohol use during pregnancy are socially patterned and are associated with children's subsequent risk of conduct problems in childhood and adolescence, with some evidence that these associations may be causal. ${ }^{14}$ A substantial proportion of women smoke during pregnancy in the UK and Denmark ${ }^{33}$ with 
smoking more prevalent among socially disadvantaged women. ${ }^{34} 35$ There are also clear inequalities in low birth weight and preterm delivery, which are associated with increased risk for childhood MHPs, potentially as a result of insults to early brain development. ${ }^{9}$

Children with chronic physical illnesses have greater vulnerability to psychosocial problems: they usually have less perceived control over the progression of the relevant disease, and are more anxious about symptom onset, peer rejection and the restriction of daily activities. ${ }^{36}$ However, in our analysis, adding childhood illness at age 7 years did not explain a substantial difference in inequalities, over and above those explained by our perinatal risk factor variables. A possible explanation is that causal pathways from childhood illness to MHPs at age 11 years might have descended from perinatal factors. It is also possible that previous evidence of the association of childhood illness and MHPs might have reflected underlying unadjusted confounding by SECs.

Maternal mental health measured up to age 7 years appeared to be an important mediator in the UK, but not Denmark. Maternal mental health is a well-established risk factor for child MHPs and has been identified as a mediator of the association between SECs and child mental health outcomes in a number of previous studies. ${ }^{15}$ In another UK birth cohort, ALSPAC (Avon Longitudinal Study of Parents and Children), MHPs showed an intergenerational pattern, that is, poor mental health could be transmitted from mothers to children. ${ }^{37}$ The lack of mediation by maternal mental health in DNBC could reflect true underlying differences between contexts, and the observed social gradient in maternal MHPs is much shallower in Denmark compared with the UK (figure 1). However, it is possible that the Kessler-6 scale used in the MCS and the ever-diagnosed psychiatric illness question used in DNBC capture different constructs. The Kessler-6 scale captures maternal mental health in the 30 days prior to the questionnaire being administered, whereas the ever-diagnosed question used in MCS captures any psychiatric illness history experienced by the mother. The Kessler-6 scale also captures other dimensions of mental health other than feeling depressed, including hopelessness, restlessness, fidgety, worthlessness and whether everything was an effort. Repeating the MCS analysis with an alternative measure of maternal reported mental reduced the PM. Future studies with more comparable mediator data could explore this finding further.

\section{Strengths and limitations}

One of the key strengths of our study is the use of two large contemporary cohorts in Europe. A wide range of information was collected in these cohorts, allowing harmonisation of variables of interest, and an examination of whether mediating mechanisms were consistent across settings. Also, as suggested by Goodman and colleagues, we also applied country-specific cut-offs for SDQ total difficulty scores to improve the validity of crosscountry comparisons. ${ }^{38}$
However, this study also has some limitations. First, as outlined above with regard to maternal mental health, differences in, and availability of, variables in our respective cohorts, limited the extent to which we could explore potential mediating pathways in a harmonised manner across both cohorts. For example, it is plausible that childhood SECs might influence mental health outcomes in late childhood/early adolescence via quality of family relationships or parenting style, which is measured in the MCS but not in the DNBC. Furthermore, data about potentially mediating childhood adversities such as domestic violence, sexual abuse and parental criminality were not available for inclusion in our analysis. Second, although we used modern methods for causal mediation analysis, and adjusted for a range of potential confounders, the assumption of complete adjustment of confounding is still required for causal interpretation of our estimates (online supplemental appendix). However, our bias analysis showed that our results are robust to presence of unmeasured confounding of moderate strength. Third, missing data is a limitation for many longitudinal studies. Nevertheless, sensitivity analysis comparing imputed and complete case analyses showed similar results. Finally, it is possible that children with mentally distressed mothers might report their children's mental health more negatively. ${ }^{39}$ As a consequence, the measured indirect effect for maternal mental health might have been inflated in this study. ${ }^{40}$

\section{Implications for policy}

The risk of child MHPs is much greater for disadvantaged children in both the UK and Denmark. Our findings suggest that public health programmes address perinatal risk factors and that support to optimal maternal mental health may reduce inequalities in child MHPs. In addition, given the unexplained residual inequality, to reduce MHPs in childhood, policy action is needed to address the upstream determinants of child mental health, with a focus on reducing socioeconomic inequalities.

Acknowledgements The authors thank the families who participated in the follow-up of the Millennium Cohort Study and the Danish National Birth Cohort and provided the valuable data. The Danish National Birth Cohort was established with a significant grant from the Danish National Research Foundation. Additional support was obtained from the Danish Regional Committees, the Pharmacy Foundation, the Egmont Foundation, the March of Dimes Birth Defects Foundation, the Health Foundation and other minor grants. The DNBC Biobank has been supported by the Novo Nordisk Foundation and the Lundbeck Foundation. Follow-up of mothers and children have been supported by the Danish Medical Research Council (SSVF 0646, 271-08-0839/06-066023, 0602-01042B, 0602-02738B), the Lundbeck Foundation (195/04, R100-A9193), The Innovation Fund Denmark 0603-00294B (09-067124), the Nordea Foundation (02-2013-2014), Aarhus Ideas (AU R9-A959-13-S804), University of Copenhagen Strategic Grant (IFSV 2012) and the Danish Council for Independent Research (DFF - 4183-00594 and DFF - 4183-00152).

Contributors ETCL did the statistical analysis and wrote the first draft with input from DT-R. ETCL, DT-R and KS-L conceptualised the study. DKS and TL helped design statistical analysis. DKS, VS, AMNA and KS-L contributed to data interpretation. All authors have critically reviewed and approved the final version of the manuscript for publication.

Funding ETCL and DTR are funded by the MRC on a Clinician Scientist Fellowship (MR/P008577/1). DKS was funded by the Cystic Fibrosis Trust (CF EpiNet SRC). TL, KS-L and A-MNA are funded by the University of Copenhagen. The funders had no 
role in study design, data collection and analysis, decision to publish or preparation of the manuscript.

Competing interests None declared.

Patient and public involvement Patients and/or the public were not involved in the design, or conduct, or reporting, or dissemination plans of this research.

Patient consent for publication Not required.

Ethics approval The MCS was reviewed and approved by appropriate research ethics committees at each wave of data collection, and parents provided written informed consent for all components of the MCS. All DNBC participants provided written consent and ethical approval was obtained from the Danish Data Protection Agency (11-year follow-up approval number: 2009-41-3339). The current study was approved by the DNBC management and Steering Committee.

Provenance and peer review Not commissioned; externally peer-reviewed.

Data availability statement Data may be obtained from a third party and are not publicly available. The data of the Millennium Cohort Study could be obtained from the UK Data Service; and the data for Danish National Birth Cohort could be obtained upon application filed to Statistics Denmark and subject to approval. Computing code could be obtained by emailing the corresponding author (ETCL).

Open access This is an open access article distributed in accordance with the Creative Commons Attribution 4.0 Unported (CC BY 4.0) license, which permits others to copy, redistribute, remix, transform and build upon this work for any purpose, provided the original work is properly cited, a link to the licence is given, and indication of whether changes were made. See: https://creativecommons.org/ licenses/by/4.0/.

\section{ORCID iDs}

Eric TC Lai http://orcid.org/0000-0002-1229-9471

Anne-Marie Nybo Andersen http://orcid.org/0000-0002-4296-8488

\section{REFERENCES}

1 Patel V, Flisher AJ, Hetrick S, et al. Mental health of young people: a global public-health challenge. Lancet 2007;369:1302-13.

2 Kieling $\mathrm{C}$, Baker-Henningham $\mathrm{H}$, Belfer $\mathrm{M}$, et al. Child and adolescent mental health worldwide: evidence for action. Lancet 2011;378:1515-25

3 Kessler RC, Berglund P, Demler O, et al. Lifetime prevalence and age-of-onset distributions of DSM-IV disorders in the National comorbidity survey replication. Arch Gen Psychiatry 2005;62:593-602.

4 Ravens-Sieberer U, Erhart M, Gosch A, et al. Mental health of children and adolescents in 12 European countries-results from the European KIDSCREEN study. Clin Psychol Psychother 2008;15:154-63.

5 Sadler K, Vizard T, Ford T, et al. Mental health of children and young people in England, 2017. NHS Digital, 2018.

6 Dalsgaard S, Nielsen HS, Simonsen M. Five-Fold increase in national prevalence rates of attention-deficit/hyperactivity disorder medications for children and adolescents with autism spectrum disorder, attention-deficit/hyperactivity disorder, and other psychiatric disorders: a Danish register-based study. J Child Adolesc Psychopharmacol 2013;23:432-9.

7 Reiss F. Socioeconomic inequalities and mental health problems in children and adolescents: a systematic review. Soc Sci Med 2013;90:24-31.

8 Viner RM, Ozer EM, Denny S, et al. Adolescence and the social determinants of health. Lancet 2012;379:1641-52.

9 Arango C, Díaz-Caneja CM, McGorry PD, et al. Preventive strategies for mental health. Lancet Psychiatry 2018;5:591-604.

10 Straatmann VS, Lai E, Lange T, et al. How do early-life factors explain social inequalities in adolescent mental health? findings from the UK millennium cohort study. J Epidemiol Community Health 2019;73:1049-60.

11 Van Lieshout RJ, Boyle MH, Saigal S, et al. Mental health of extremely low birth weight survivors in their $30 \mathrm{~S}$. Pediatrics 2015;135:452-9.

12 Dibben C, Sigala M, Macfarlane A. Area deprivation, individual factors and low birth weight in England: is there evidence of an "area effect"? J Epidemiol Community Health 2006;60:1053-9.

13 Mortensen LH, Diderichsen F, Arntzen A, et al. Social inequality in fetal growth: a comparative study of Denmark, Finland, Norway and Sweden in the period 1981-2000. J Epidemiol Community Health 2008;62:325-31.
14 Dolan CV, Geels L, Vink JM, et al. Testing causal effects of maternal smoking during pregnancy on offspring's Externalizing and internalizing behavior. Behav Genet 2016;46:378-88.

15 Wickham S, Whitehead M, Taylor-Robinson D, et al. The effect of a transition into poverty on child and maternal mental health: a longitudinal analysis of the UK millennium cohort study. Lancet Public Health 2017;2:e141-8.

16 Secinti E, Thompson EJ, Richards M, et al. Research Review: Childhood chronic physical illness and adult emotional health - a systematic review and meta-analysis. J Child Psychol Psychiatry 2017;58:753-69.

17 Mäntymaa M, Puura K, Luoma I, et al. Predicting internalizing and externalizing problems at five years by child and parental factors in infancy and toddlerhood. Child Psychiatry Hum Dev 2012;43:153-70.

18 Centre for Longitudinal Studies. Millennium cohort study sixth sweep (Mcs6) technical report. London: Institute of Education, University College London, 2017.

19 Olsen J, Melbye M, Olsen SF, et al. The Danish National Birth Cohort - its background, structure and aim. Scand J Public Health 2001;29:300-7

20 Pearce A, Dundas R, Whitehead M, et al. Pathways to inequalities in child health. Arch Dis Child 2019;104:998-1003.

21 Poulsen G, Strandberg-Larsen K, Mortensen L, et al. Exploring educational disparities in risk of preterm delivery: a comparative study of 12 European birth cohorts. Paediatr Perinat Epidemiol 2015;29:172-83.

22 Hayes LJ, Berry G. Sampling variability of the Kunst-Mackenbach relative index of inequality. J Epidemiol Community Health 2002;56:762-5.

23 Koskelainen M, Sourander A, Kaljonen A. The strengths and difficulties questionnaire among Finnish school-aged children and adolescents. Eur Child Adolesc Psychiatry 2000;9:277-84.

24 Goodman R. The strengths and difficulties questionnaire: a research note. J Child Psychol Psychiatry 1997;38:581-6.

25 Arnfred J, Svendsen K, Rask C, et al. Danish norms for the strengths and difficulties questionnaire. Dan Med J 2019;66.

26 Hernán MA, Hernández-Díaz S, Werler MM, et al. Causal knowledge as a prerequisite for confounding evaluation: an application to birth defects epidemiology. Am J Epidemiol 2002;155:176-84.

27 Steen J, Loeys T, Moerkerke B, et al. medflex:An $R$ Package for Flexible Mediation Analysis using Natural Effect Models. J Stat Softw $2017 ; 76$.

28 VanderWeele T. Explanation in causal inference: methods for mediation and interaction. Oxford University Press, 2015.

29 VanderWeele TJ. Bias formulas for sensitivity analysis for direct and indirect effects. Epidemiology 2010;21:540-51.

30 The Children's Society. The good childhood report. London, UK, 2018.

31 Brekke KA, Grünfeld LA, Kverndokk S. Explaining the health equality paradox of the welfare state. Oslo: Health economics research programme, University of Oslo, 2012.

32 Easey KE, Dyer ML, Timpson NJ, et al. Prenatal alcohol exposure and offspring mental health: a systematic review. Drug Alcohol Depend 2019;197:344-53.

33 Euro-Peristat Project, SCPE, Eurocat. European perinatal health report. The health and care of pregnant women and babies in Europe in 2010, 2013.

34 Bilsteen JF, Andresen JB, Mortensen LH, et al. Educational disparities in perinatal health in Denmark in the first decade of the 21st century: a register-based cohort study. BMJ Open 2018;8:e023531.

35 Taylor-Robinson DC, Pearce A, Whitehead M, et al. Social inequalities in wheezing in children: findings from the UK millennium cohort study. Eur Respir J 2016;47:818-28.

36 Pinquart M, Shen Y. Behavior problems in children and adolescents with chronic physical illness: a meta-analysis. J Pediatr Psychol 2011;36:1003-16.

37 Plant DT, Jones FW, Pariante CM, et al. Association between maternal childhood trauma and offspring childhood psychopathology: mediation analysis from the ALSPAC cohort. $\mathrm{Br} J$ Psychiatry 2017;211:144-50.

38 Goodman A, Heiervang E, Fleitlich-Bilyk B, et al. Cross-National differences in questionnaires do not necessarily reflect comparable differences in disorder prevalence. Soc Psychiatry Psychiatr Epidemiol 2012;47:1321-31.

39 Najman JM, Williams GM, Nikles J, et al. Bias influencing maternal reports of child behaviour and emotional state. Soc Psychiatry Psychiatr Epidemiol 2001;36:186-94.

40 Hernán MA, Cole SR. Invited commentary: causal diagrams and measurement bias. Am J Epidemiol 2009;170:959-62. 
41 Gallagher C, McCarthy FP, Ryan RM, et al. Maternal alcohol consumption during pregnancy and the risk of autism spectrum disorders in offspring: a retrospective analysis of the millennium cohort study. J Autism Dev Disord 2018;48:3773-82.

42 Sun Y, Strandberg-Larsen K, Vestergaard M, et al. Binge drinking during pregnancy and risk of seizures in childhood: a study based on the Danish national birth cohort. Am J Epidemiol 2009;169:313-22.

43 Hansen K. Centre for Longitudinal Studies. In: Millennium Cohort Study - A Guide to the Datasets. (eighth edition): first, second, third, fourth and fifth surveys. London: University of London, 2014.

44 Boyle EM, Poulsen G, Field DJ, et al. Effects of gestational age at birth on health outcomes at 3 and 5 years of age: population based cohort study. BMJ 2012;344:e896.

45 Kessler RC, Andrews G, Colpe LJ, et al. Short screening scales to monitor population prevalences and trends in non-specific psychological distress. Psychol Med 2002;32:959-76. 